\title{
Actions of Substance P on Rat Neostriatal Neurons In Vitro
}

\author{
Toshihiko Aosaki and Yasuo Kawaguchi \\ Laboratory for Neural Circuits, Bio-Mimetic Control Research Center, The Institute of Physical and Chemical Research \\ (RIKEN), Nagoya, Aichi 456, Japan
}

\begin{abstract}
Actions of substance $\mathrm{P}(\mathrm{SP})$ on the neostriatal neurons in in vitro rat slice preparations were studied via whole-cell patch-clamp recording. Almost all large aspiny neurons (cholinergic cells) and half of the low-threshold spike (LTS) cells (somatostatin/ NOS-positive cells) showed depolarization or an inward shift of the holding currents in response to bath-applied SP in a dosedependent manner. In contrast, no responses were observed in fast-spiking (FS) cells (parvalbumin-positive cells) and medium spiny cells. Spike discharges followed by slow EPSPs/EPSCs were evoked by intrastriatal electrical stimulation in the large aspiny neurons. Pretreatment with $\left[\mathrm{D}-\mathrm{Arg}^{1}, \mathrm{D}-\mathrm{Pro}^{2}, \mathrm{D}-\right.$ $\operatorname{Trp}^{7,9}$, Leu $^{11}$ ]-SP, an antagonist of the SP receptor, reversibly suppressed the induction of the slow EPSPs/EPSCs and unmasked slow IPSCs. The SP-induced inward current, although
\end{abstract}

almost unchanged even after the blockade of $I_{\mathrm{h}}$ channels and voltage-dependent $\mathrm{Na}^{+}, \mathrm{Ca}^{2+}$, and $\mathrm{K}^{+}$channels, changed its amplitude according to the $\mathrm{Na}^{+}$concentration used in both the large aspiny neurons and LTS cells. Thus, the cation current could account for virtually all of the inward current at resting levels in both neurons. These results suggest that the firing of afferent neurons such as striatonigral medium spiny neurons, one of the possible sources of SP, would increase the firing probability of the two types of interneurons of the neostriatum by SP-receptor-mediated opening of tetrodotoxin-insensitive cation channels.

Key words: striatum; basal ganglia; cholinergic; somatostatin; interneurons; substance P; tachykinin; neuropeptide; cations; slice preparations; patch clamp
The undecapeptide substance $\mathrm{P}$ (SP), one of the neuropeptides known as tachykinins, is thought to play an important role as a neurotransmitter/neuromodulator in the CNS (Otsuka and Yoshioka, 1993). Evidence suggests that SP-containing fiber terminals in the striatum originate from thalamocaudate neurons in the center median-parafascicular complex (Sugimoto et al., 1984). There are two distinct populations of SP-containing medium-sized neurons in the striatum: the striatonigral medium-sized spiny projection neurons (Hong et al., 1977; Brownstein et al., 1983; Gerfen and Young, 1988) and the medium-sized aspiny interneurons with indented nuclei (Bolam et al., 1983). The striatum has also been shown to contain three G-protein-coupled neurokinin receptor subtypes: NK1, NK2, and NK3, among which SP preferentially binds to the first. The NK1 receptor is not expressed, however, in the medium spiny neurons but, rather, in the somatostatinergic and large cholinergic interneurons of the striatum of the rat (Gerfen, 1991; Kaneko et al., 1993), as well as nonhuman primates and human (Aubry et al., 1994; Parent et al., 1995). Both cell types have been reported to have synapses on their somatodendritic trees at the SP-containing terminals (Bolam and Izzo, 1988). However, the cholinergic neurons are especially important because, although they represent only a small population in the striatum, their widespread dendritic and axonal fields, high sensitivity to small depolarizing potentials (Wilson et al., 1990), and modu-

\footnotetext{
Received Jan. 16, 1996; revised May 3, 1996; accepted May 21, 1996.

This work was supported by the Frontier Research Program and Grants-in-Aid $07458217 \mathrm{~B}$ and 07279250 for Scientific Research on the Priority Area of "Functional Development of Neural Circuits" of the Ministry of Education, Science, Sports and Culture of Japan. We thank Ms. Naoko Wada, who carried out the histology, and we thank Dr. Yoshiyuki Kubota for helpful discussion.

Correspondence should be addressed to Dr. Toshihiko Aosaki, Laboratory for Neural Circuits, Bio-Mimetic Control Research Center, The Institute of Physical and Chemical Research (RIKEN), 3-8-31, Rokuban, Atsuta, Nagoya, Aichi 456, Japan. Copyright (C) 1996 Society for Neuroscience $0270-6474 / 96 / 165141-13 \$ 05.00 / 0$
}

lation of tonic firing in response to conditioned sensory cues (Aosaki et al., 1994a,b, 1995; Graybiel et al., 1994) suggest that they act as important modulators of basal ganglia function.

Although several lines of evidence have confirmed that SP increases the firing rate of some striatal neurons and elicits the release of acetylcholine in the rat neostriatum (Le Gal La Salle and Ben-Ari, 1977; Arenas et al., 1991; Anderson et al., 1993; Guevara Guzman et al., 1993), not a single electrophysiological study has been made to reveal the actions of SP on the large aspiny neurons and/or other types of neurons in the striatum. Electrophysiological studies on neurons in the other brain areas have shown that SP modulates several ionic conductances, and that the ionic mechanisms of SP actions differ considerably among neuronal types (Adams et al., 1983; Stanfield et al., 1985; Bley and Tsien, 1990; Shen and North, 1992; Bertrand and Galligan, 1994).

The present study, therefore, was aimed at elucidating what types of neurons in the striatum respond to SP, and what the ionic mechanisms of the actions of SP are. To this end, we made whole-cell patch-clamp recordings from identified rat neostriatal neurons in slice preparations and found that SP evokes an excitatory response by the large aspiny cholinergic interneurons and somatostatinergic interneurons, but not the medium spiny neurons and parvalbumin-containing neurons, and that it achieves its slow excitatory effect mainly by opening tetrodotoxin (TTX)insensitive cation channels.

Some of these data have been published previously in abstract form (Aosaki and Kawaguchi, 1995).

\section{MATERIALS AND METHODS}

Slice preparations. Experiments were made on $200-\mu \mathrm{m}$-thick sagittal rat brain slices containing the striatum. The age of the rats (Wistar) used ranged from 15 to $22 \mathrm{~d}$ old. The methods for preparation and maintenance of the striatal slices were similar to those described previously 
(Kawaguchi, 1992). Briefly, the animals were deeply anesthetized with ether and decapitated. The brains were quickly removed and submerged in ice-cold physiological Ringer's solution oxygenated with a mixture of $95 \% \mathrm{O}_{2} / 5 \% \mathrm{CO}_{2}$. Slices were superfused with physiological saline at $33^{\circ} \mathrm{C}$ at $3 \mathrm{ml} / \mathrm{min}$. The solution comprised (mM): $\mathrm{NaCl} \mathrm{124,} \mathrm{KCl} 3, \mathrm{CaCl}_{2} 2.4$, $\mathrm{MgCl}_{2} 1.2, \mathrm{NaH}_{2} \mathrm{PO}_{4} 1, \mathrm{NaHCO}_{3} 26$, glucose 10 , oxygenated with $95 \%$ $\mathrm{O}_{2} / 5 \% \mathrm{CO}_{2}$

Whole-cell recordings. Whole-cell recordings were made with glass pipettes (3-4 M $\Omega$ ), which contained (mM): K-methylsulfate $120, \mathrm{KCl} 6$, $\mathrm{NaCl} 6$, EGTA 0.6, HEPES 10, $\mathrm{MgCl}_{2} 2$, ATP 4, GTP 0.3, biocytin $20(\mathrm{pH}$ 7.2). TTX was sometimes added to the external solution at $0.3 \mu \mathrm{M}$. When the ion substitution experiment was performed, $\mathrm{NaCl}$ was replaced with choline chloride in low-sodium external solutions. When replacing $\mathrm{CaCl}_{2}$ with $\mathrm{CoCl}_{2}, \mathrm{NaH}_{2} \mathrm{PO}_{4}$ was omitted. To isolate the nonselective cation current, tetraethylammonium chloride (TEA-Cl) 30, 4-aminopyridine (4-AP) $10, \mathrm{CsCl} 2, \mathrm{MgCl}_{2} 3.6$, no $\mathrm{Ca}^{2+}$ (all in $\mathrm{mM}$ ), and TTX $0.3 \mu \mathrm{M}$ were added to the external solution, and Cs-methanesulfonate or TEA-Cl was substituted for K-methylsulfate in the pipette solution. Nifedipine was occasionally added to the external solution. When Cs-methanesulfonate or TEA-Cl was substituted for K-methylsulfate, $\mathrm{CsOH}$ and TEA-OH, respectively, were used to adjust the $\mathrm{pH}$. Membrane potentials and currents evoked by SP were recorded with an EPC-7 amplifier (List Biologic, Campbell, CA). Series resistance was compensated for partially by the amplifier. The given membrane potentials were corrected for the junction potential between the pipette solution and the bath solution before making a gigaseal (usually the pipette was $5 \mathrm{mV}$ negative to the bath). Membrane conductance was measured from the slope of the chord in $\pm 5 \mathrm{mV}$ step pulses. Bipolar tungsten electrodes were placed in the neostriatum to record synaptic responses from the identified large aspiny neurons. Stimulation experiments were not attempted for other classes of neostriatal interneurons because of the difficulty in sampling a sufficient number of the neurons. The focal electrical stimulation was made with $1-7 \mathrm{~V}$ pulses of $0.5 \mathrm{msec}$ duration at $20 \mathrm{~Hz}$ for up to $500 \mathrm{msec}$ (10 pulses). Occasionally, only one or a few pulses were applied to compare with the evoked synaptic responses to 10 pulses. To exclude the possibility that any changes in membrane properties occurred during treatment of [D-Arg ${ }^{1}, \mathrm{D}-$ Pro $^{2}$, D-Trp ${ }^{7,9}$, Leu $^{11}$ ]-SP (Sigma, St. Louis, MO), an antagonist of the SP receptor, membrane conductance was monitored in later experiments by current levels evoked by hyperpolarizing step pulses of $5 \mathrm{mV}$ and fast synaptic currents evoked by stimulating electrical test pulses weak enough to prevent spike firing.

Electrophysiological identification of the neostriatal neurons. Neurons in the neostriatum were visualized using a $40 \times$ water immersion objective. Particular attention was paid to preferentially recording neurons larger than the most abundant cells, the medium spiny neurons (MS cells). Electrophysiological criteria for identification of the neostriatal neurons of the rat were described in detail previously (Kawaguchi, 1992, 1993). Briefly, the cells that had a resting potential of about $-60 \mathrm{mV}$ and displayed long-lasting afterhyperpolarizations and strong time-dependent hyperpolarizing rectification were classified as long-lasting afterhyperpolarization cells (LA cells) and those with a resting potential of about -60 $\mathrm{mV}$, which demonstrated low-threshold burst discharges at the beginning of depolarizing pulses along with weak time-dependent hyperpolarizing rectification and shorter afterhyperpolarizations compared with LA cells were considered as low-threshold spike cells (LTS cells). Both cell types showed prominent depolarizing humps, occasionally accompanied by spike discharges, after cessation of hyperpolarizing pulses. The cells with more negative resting potentials $(-80 \mathrm{mV})$, which fired very short action potentials with short afterhyperpolarizations and had no time-dependent hyperpolarizing sag, were classified as fast-spiking cells (FS cells). The most abundant MS cells showed more negative resting potentials $(-80$ $\mathrm{mV}$ ), a larger spike threshold from the resting membrane potential, and a prominent inward rectification. Immunohistochemical evidence has indicated that LA cells are large aspiny cholinergic interneurons, that LTS cells are somatostatin/nitric oxide synthase (NOS)-immunoreactive cells, and that FS cells are parvalbumin-immunoreactive cells (Kawaguchi, 1992, 1993).

Histochemical procedures. In an attempt to identify the recorded cells morphologically, $20 \mathrm{~mm}$ biocytin was included in the pipette solution so that they were filled by diffusion (Horikawa and Armstrong, 1988). Slices containing biocytin-filled cells were fixed by immersion in $4 \%$ paraformaldehyde and $0.2 \%$ picric acid in $0.1 \mathrm{M}$ phosphate buffer $(\mathrm{PB})$ overnight in at $4{ }^{\circ} \mathrm{C}$, rinsed in $\mathrm{PB}$ for $30 \mathrm{~min}$, and incubated in $\mathrm{PB}$ containing $0.5 \%$ $\mathrm{H}_{2} \mathrm{O}_{2}$ for 30 min to suppress endogenous peroxidase activity. They were then incubated in 10 and $20 \%$ sucrose for $30 \mathrm{~min}$ and $1 \mathrm{hr}$, respectively, frozen, and stored in a freezer until histochemistry was carried out. The slices, without resectioning, were then washed with Tris-buffered saline (TBS) containing $0.5 \%$ Triton X-100 and avidin-biotin-peroxidase complex (ABC; Vector Laboratories; Burlingame, CA) at a dilution of 1:100 for 4-6 hr at room temperature. After rinsing, the slices were reacted with 3,3'-diaminobenzidine tetrahydrochloride (DAB; 0.05\%) and $\mathrm{H}_{2} \mathrm{O}_{2}$ $(0.003 \%)$ in TBS, post-fixed in $0.1 \%$ osmium tetroxide in $0.1 \mathrm{M}$ PB for 5 min, and mounted on slides.

Drugs. SP and other agents such as $\mathrm{CsCl}, \mathrm{CoCl}_{2}, \mathrm{TTX}$, and nifedipine were applied by changing the solution superfusing the slice to one that contained the drug. Time taken to reach the neurons was usually $<1 \mathrm{~min}$. Drugs used were SP (Sigma), [D-Arg ${ }^{1}$, D-Pro ${ }^{2}$, D-Trp ${ }^{7,9}$, Leu $^{11}$ ]-SP (Sigma), TTX (Sankyo), 4-aminopyridine (Sigma), TEA-Cl (Nakarai Tesque), and nifedipine (Sigma).

Results are expressed as mean $\pm \mathrm{SD}$, and comparisons between groups were made using Student's $t$ test.

\section{RESULTS}

\section{Physiological and morphological identification of the large aspiny neurons}

Whole-cell patch-clamp recordings from visually identified neurons in slice preparations (Edwards et al., 1989) allowed us to examine a number of neurons from small populations of specific neuronal classes such as the large aspiny cholinergic interneuron, which accounts for only $\sim 2 \%$ of the total neuronal population in the rat neostriatum (Kemp and Powell, 1971; Phelps et al., 1985).

Of a total of 242 rat neostriatal neurons recorded, 226 were identified as large aspiny cholinergic interneurons (long-lasting afterhyperpolarization, LA cells), 7 as low-threshold spike cells (LTS, somatostatin/nitric oxide-immunoreactive cells), 3 as fastspiking cells (FS, parvalbumin-immunoreactive neurons), and 6 as medium-sized spiny projection neurons (MS cells). The large aspiny cells had resting membrane potentials of about $-60 \mathrm{mV}$, larger input resistances, lower thresholds for spike generation, and longer-duration and larger-amplitude afterhyperpolarizations than other classes of neurons. During hyperpolarizing current pulses, they showed a characteristic prominent sag, which was demonstrated to be attributable to activation of hyperpolarizationactivated cation currents $\left(I_{\mathrm{h}}\right)$ (Jiang and North, 1991; Kawaguchi, 1993) (Fig. 1Ba, Bb). Subsequently, staining with biocytin revealed large somata with aspiny or sparsely spiny dendrites as depicted in Figure $1 A$.

\section{Slow postsynaptic potentials}

To determine whether SP actually serves as a neurotransmitter and neuromodulator in the neostriatum, we positioned one or two bipolar electrodes intrastriatally and recorded synaptic responses by stimulation of afferent fibers to the large aspiny cells. Electrical stimulation successfully induced initial fast EPSPs/EPSCs in a total of 24 cells with spikes followed by slow EPSPs/EPSCs. Figure 2 shows results for examples of cells with slow EPSPs/EPSCs $(A$ : current clamp; $B, C$ : voltage clamp at $-60 \mathrm{mV})$. Electrical stimulation $(0.5 \mathrm{msec}$ rectangular pulses at $20 \mathrm{~Hz}$ for $500 \mathrm{msec}, 10$ pulses) produced fast $\mathrm{Na}^{+}$spikes followed by a slow EPSP/EPSC with repetitive spike discharges, which lasted for $\sim 50 \sec (54.5 \pm$ $19.5 \mathrm{sec}, n=17)$. This long-lasting EPSP/EPSC was greatly blocked by bath-applied [D-Arg ${ }^{1}, \mathrm{~d}-\mathrm{Pro}^{2}, \mathrm{D}-\operatorname{Trp}^{7,9}, \mathrm{Leu}^{11}$ ]-SP (10 $\mu \mathrm{M}$ in $A$ and $B, 20 \mu \mathrm{M}$ in $C$ ), a structural analog with antagonist properties, and fully recovered $10 \mathrm{~min}$ after washout of the drug. Its effect was tested in 16 of the total of 24 cells, and 10 cells showed reduction of the slow inward current. This suppression of the slow EPSP/EPSC by the antagonist was not accompanied by any change in membrane properties as shown in Figure $2 B$ (inset). The current levels evoked by hyperpolarizing step pulses of $5 \mathrm{mV}$ did not change during treatment (Fig. $2 B$, inset, left). When the 


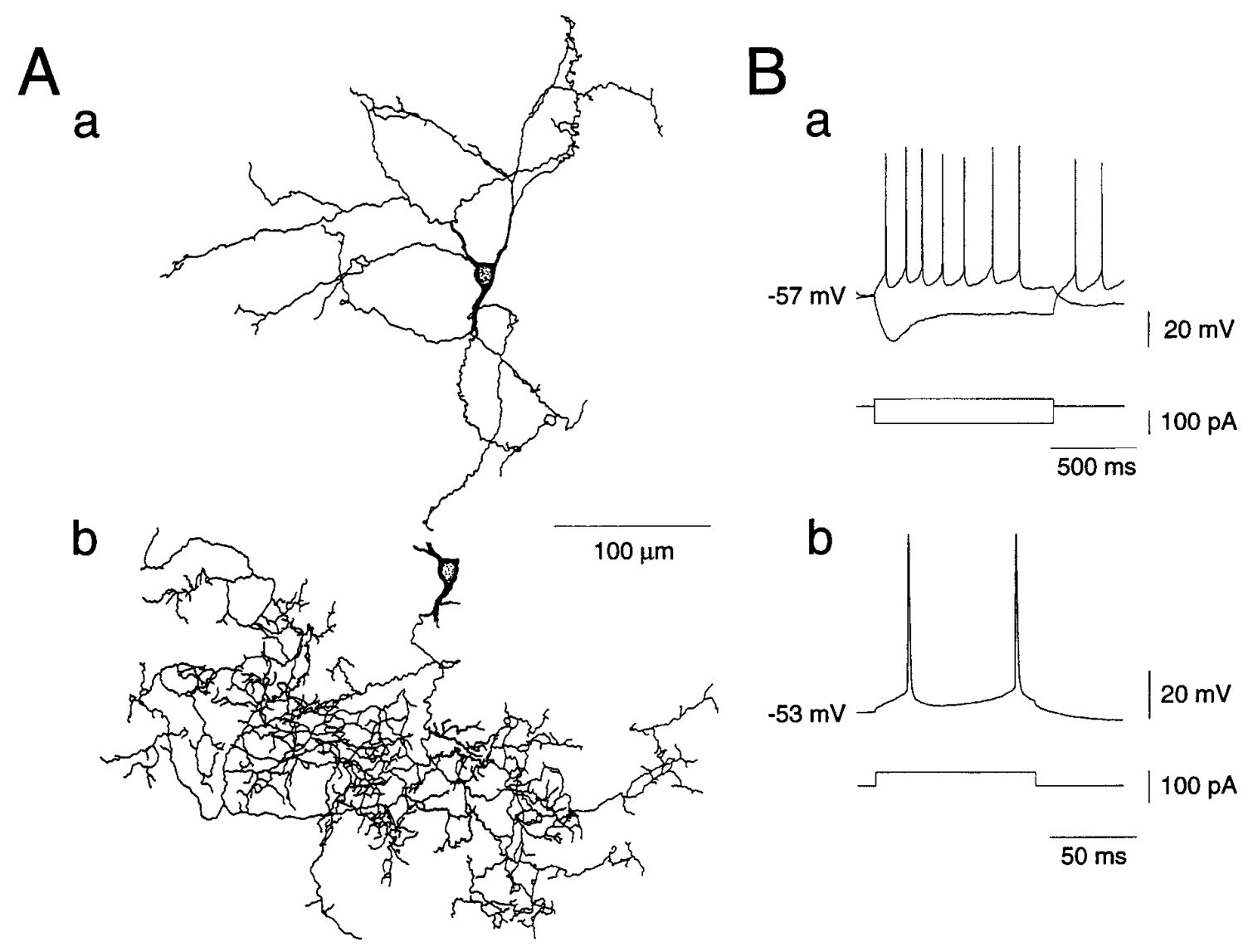

Figure 1. Reconstruction of a large aspiny neuron of the rat neostriatum that was stained with biocytin during whole-cell recording $(A)$. Dendrites $(a)$ and an axon $(b)$ are shown separately. $B$, Membrane properties of the same cell in response to constant-current pulses applied intracellularly. The resting membrane potentials (approximately $-60 \mathrm{mV}$ ), input resistances $(\sim 430 \mathrm{M} \Omega)$, as well as the long-duration, large-amplitude afterhyperpolarization and the prominent sag during hyperpolarizing current pulses all fit well with the physiological properties of large aspiny neurons (long-lasting afterhyperpolarization, LA cells).

intensity of the stimulating electrical pulses was adjusted to evoke fast synaptic currents, but not spike discharges, to allow monitoring of the former, no significant change was observed (see Fig. $2 B$, inset, right). This suggests that at least a part of the slow EPSP/ EPSC evoked by electrical stimulation was probably elicited by SP released from the afferent fibers to the cells recorded. When voltage-clamped at $-75 \mathrm{mV}$, the evoked slow EPSCs augmented, indicating a reversal potential more positive than $-60 \mathrm{mV}$. Interestingly, a slow outward component appeared during treatment with the SP analog in 2 out of 10 cells that showed reduction of the slow EPSC. The cell shown in Figure $2 C$ showed a slow suppressed inward current combined with outward current when it was bathed in $20 \mu \mathrm{M}$ of the SP antagonist, whereas it exhibited only a slow inward current in the control and recovery phases. In another case (data not shown), although the cell exhibited initial fast $\mathrm{Na}^{+}$spikes followed by a small inward current when a single pulse was applied, 10 pulses at $20 \mathrm{~Hz}$ evoked a slow outward current after the initial spike currents. Application of [D-Arg ${ }^{1}, \mathrm{D}-$ Pro $^{2}, \mathrm{D}-\operatorname{Trp}^{7,9}, \mathrm{Leu}^{11}$ ]-SP further enhanced this outward component in a dose-dependent manner. This is in line, although not exclusively, with the interpretation that the repetitive stimulation further recruited some slowly acting inhibitory substances from the afferent fibers and that the antagonist unmasked the outward current by reducing the SP-evoked inward current. Also, the fact that 6 of 16 cells tested with the SP antagonist showed no reduc- tion of the slow EPSC amplitude and that some cells showed only a partial reduction suggest that there are some other substances released from the afferent fibers that evoke slow EPSC.

\section{Pharmacological evidence for SP as a neurotransmitter/neuromodulator in the neostriatum}

To confirm further that SP indeed acts as an excitatory neurotransmitter on the large aspiny cells, we bath-applied SP at various concentrations and made recordings. As shown in Figure $3 A$, SP evoked membrane depolarization ( $a$, current clamp) or an inward current ( $b$, voltage clamp with $0.3 \mu \mathrm{M}$ TTX) in all cells tested (163/163 cells). Its effect was dependent on the concentration of the peptide with an $\mathrm{EC}_{50}$ of $\sim 100 \mathrm{~nm}$ as shown in Figure 4. The excitatory response was accompanied by an increase or by no change in input conductance. Pretreatment with the SP antagonist $\left[\mathrm{D}-\mathrm{Arg}^{1}, \mathrm{D}-\mathrm{Pro}^{2}, \mathrm{D}-\operatorname{Trp}^{7,9}, \mathrm{Leu}^{11}\right]$-SP in a TTX-containing solution suppressed the SP-induced inward current in a dose-dependent manner (Fig. 3B), suggesting that it was a direct response to SP.

\section{Current-voltage relationship before and during application of substance $\mathbf{P}$}

When the large aspiny neurons were voltage-clamped at or near the resting membrane potential $(-60 \mathrm{mV})$, bath application of SP for $\sim 1$ min produced an inward shift of the holding current. Its 

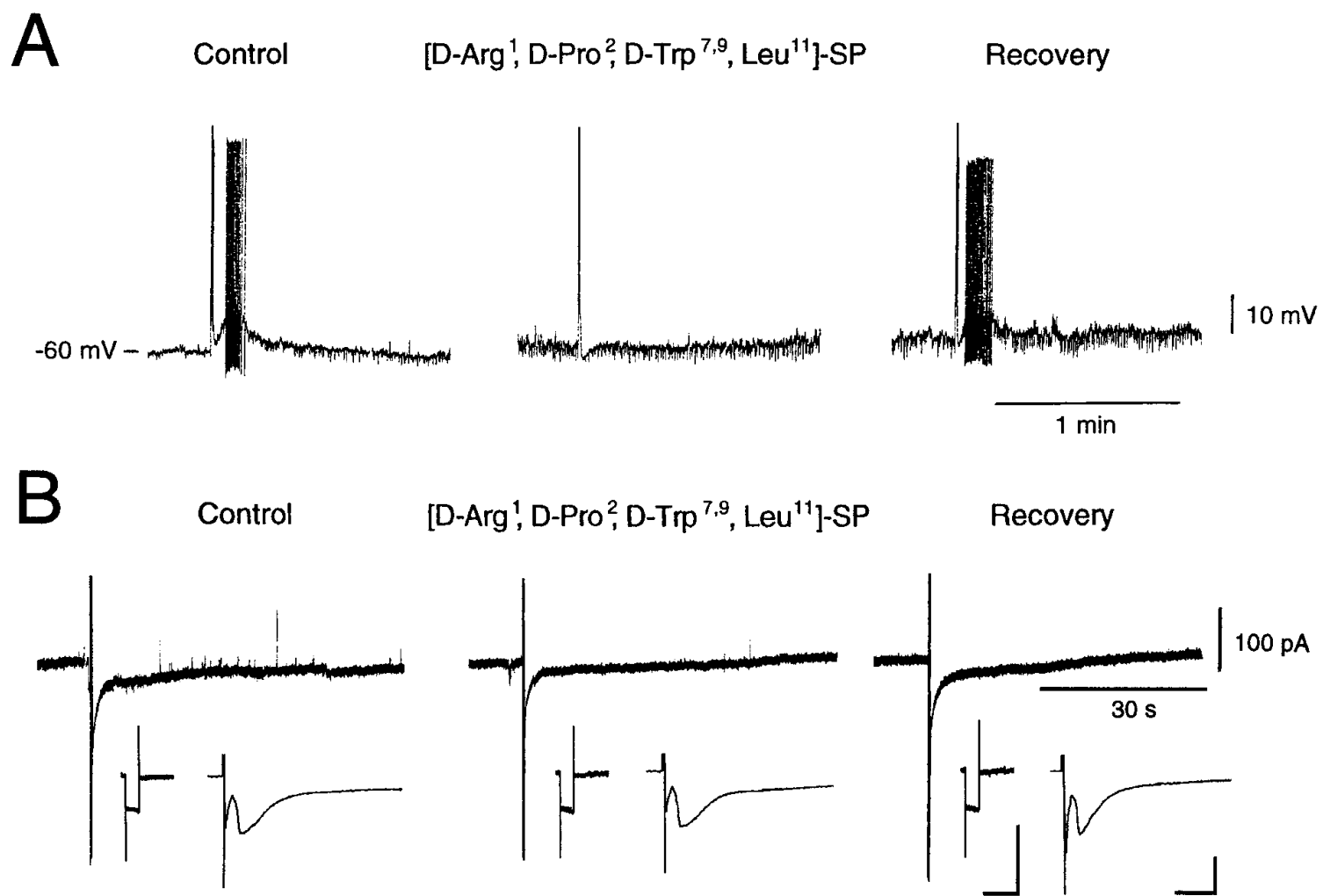

[D-Arg, D-Pro', D-Trp ${ }^{7,9}$, Leu $\left.^{11}\right]-S P$

Recovery
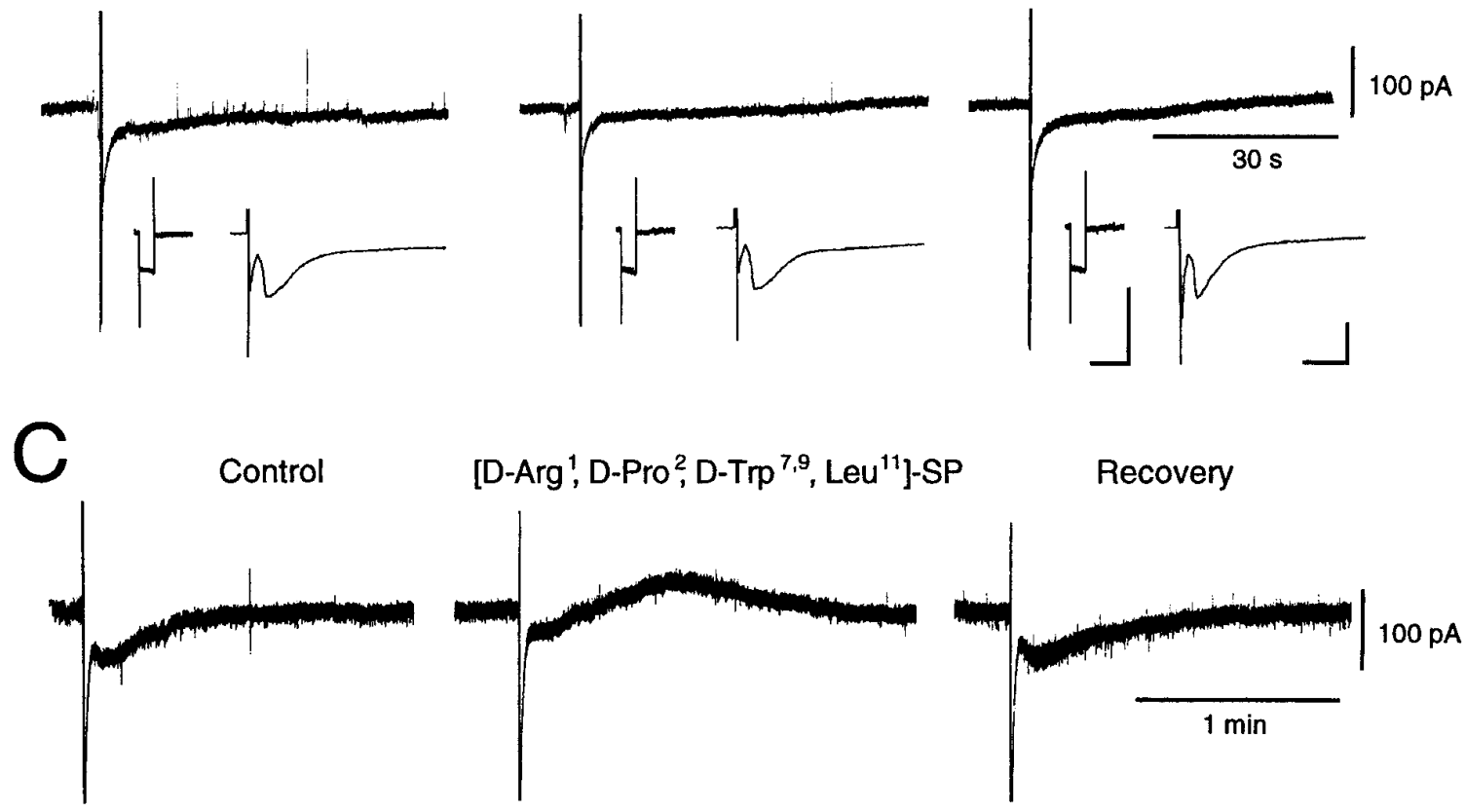

Figure 2. Responses of large aspiny neurons to intrastriatal stimulation. $A$, Intrastriatal stimulation (10 pulses of $0.5 \mathrm{msec}$ duration, $20 \mathrm{~Hz}$ ) elicited a slow EPSP with action potentials in a large aspiny neuron in the current-clamp mode. Pretreatment with [D-Arg $\left.{ }^{1}, \mathrm{D}^{-} \mathrm{Pro}^{2}, \mathrm{D}^{-} \operatorname{Trp}^{7,9}, \mathrm{Leu}^{11}\right]-\mathrm{SP}(10 \mu \mathrm{M})$, an antagonist for the NK1 receptor, suppressed this completely and reversibly. $B$, Intrastriatal repetitive stimulation elicited a slow EPSP in the voltage-clamp mode (holding potential, $-60 \mathrm{mV})$, and $\left[\mathrm{D}-\mathrm{Arg}^{1}, \mathrm{D}-\mathrm{Pro}^{2}, \mathrm{D}-\operatorname{Trp}^{7,9}, \mathrm{Leu}^{11}\right]-\mathrm{SP}(10 \mu \mathrm{M})$ suppressed this reversibly. Inset: Left, Membrane currents elicited by hyperpolarizing step pulses of $5 \mathrm{mV}$. Calibration: $1 \mathrm{sec}$ (horizontal), $100 \mathrm{pA}$ (vertical). Note that membrane conductance did not change throughout the experiment. Right, Fast excitatory synaptic currents elicited by single test pulses of the same intensity $(\sim 250$ A) as that of repetitive pulses for the slow EPSC. Calibration: $10 \mathrm{msec}$ (horizontal), $100 \mathrm{pA}$ (vertical). Intensity of the stimulating pulses was adjusted to evoke fast synaptic currents but suppress spike firing in this cell. Note that the fast synaptic currents did not change their amplitude during the treatment. $C$, Slow postsynaptic responses consist of excitatory and inhibitory components. Treatment with [D-Arg $\left.{ }^{1}, \mathrm{D}-\mathrm{Pro}^{2}, \mathrm{D}-\mathrm{Trp}^{7,9}, \mathrm{Leu}^{11}\right]-\mathrm{SP}(20 \mu \mathrm{M})$ unmasked an inhibitory component, and removal of the antagonist resulted in complete recovery.

effect usually reached a peak within $1-2$ min, then exhibited a small desensitization and almost completely recovered within 10 min of washout. The effect could be elicited several times by repeated application of the peptide, although with a progressive deterioration of the response. As depicted in Figure $5 A$, the cells showed a prominent slow inward relaxation (arrows in Fig. $5 A$, middle) in response to $1 \mathrm{sec}$ hyperpolarizing voltage commands and a prominent outward tail current (arrowheads in Fig. $5 A$, middle) after cessation of these commands $(-70,-100 \mathrm{mV})$. Depolarizing voltage steps to -40 and $-10 \mathrm{mV}$ from a holding potential of $-55 \mathrm{mV}$ evoked a rapidly decaying inward current (asterisks in Fig. 5A, middle) and a slow inward relaxation. Bath application of SP induced an inward shift of the holding current and appeared to cause reduction of the initial inward current evoked by depolarizing voltage commands, but little change in the slow inward relaxation and outward tail attributable to hyperpolarizing voltage commands (Fig. $5 A$, right). Steady-state $I-V$ plots before and during SP administration are shown in Figure $5 B$. The slope conductance increased along with the amplitude of depolarizing voltage pulses, indicating an outward rectification, but plots in the subthreshold region of membrane potentials displayed a fairly linear $I-V$ relationship with a slight tendency to inward rectification. Little change in membrane conductance at the resting level was observed after SP administration. A curve for SP- 


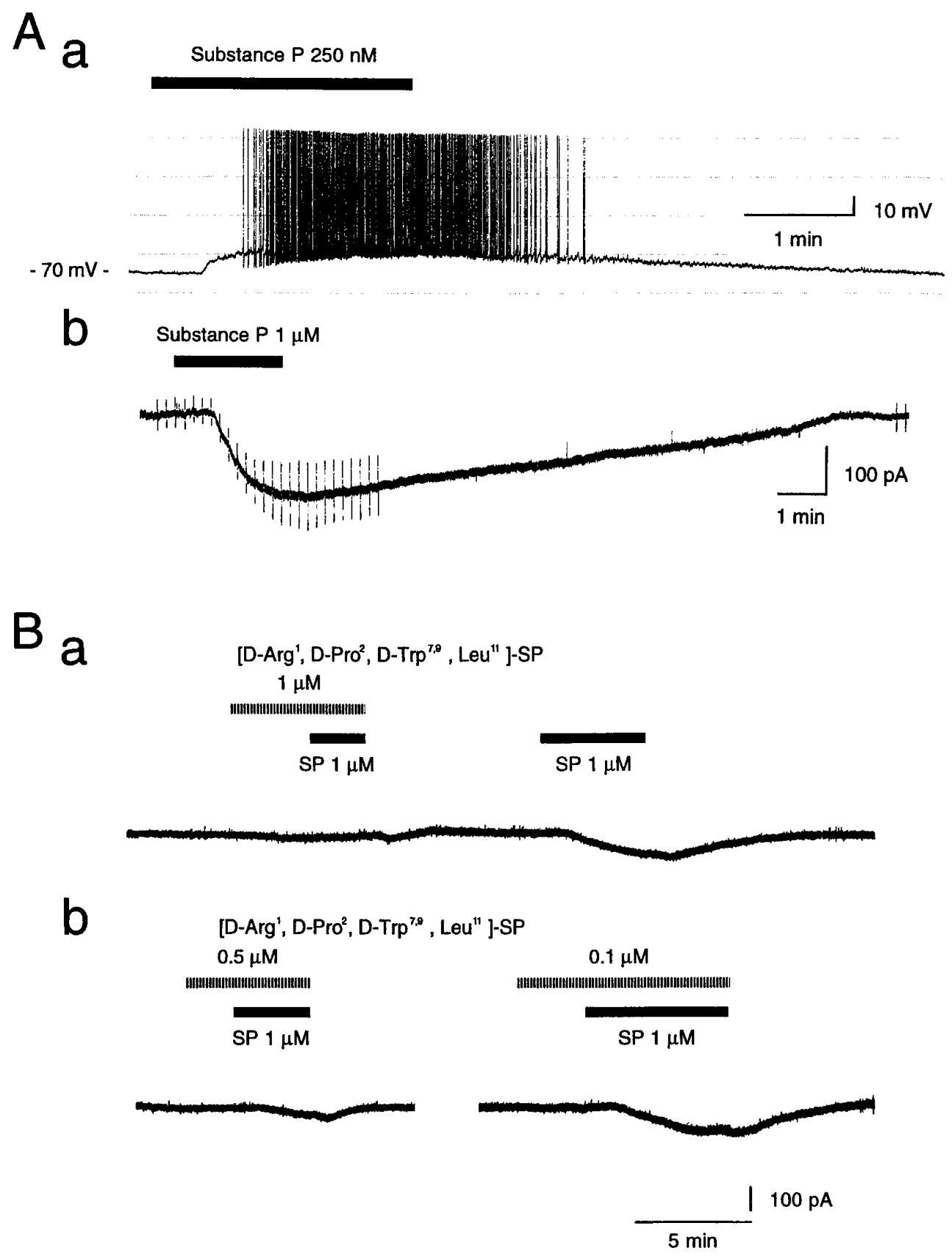

Figure 3. Effects of substance $\mathrm{P}$ on large aspiny neurons. $A$, Substance $\mathrm{P}$ evoked depolarization in the current-clamp mode $(a)$ and elicited an inward current in the voltage-clamp mode $(-60 \mathrm{mV})(b)$. TTX $(0.3 \mu \mathrm{M})$ was also applied in $b$. Note that membrane conductance increased after application of SP. Depolarizing and hyperpolarizing voltage pulses $( \pm 10 \mathrm{mV}, 100 \mathrm{msec})$ were applied before and during SP application. $B$, Pretreatment with an SP antagonist suppressed the SP-induced inward current in a dose-dependent manner. The recordings in $a$ and $b$ are for the same cell.

induced change in current responses $\left(I_{\mathrm{SP}}\right)$, constructed by subtracting the $I-V$ curve obtained before SP application from the curve obtained during the peptide application, is superimposed in Figure $5 B$. The SP-induced inward current showed a complex voltage dependency at hyperpolarized levels and did not reverse its polarity.

\section{What types of channels contribute to the SP-induced inward current?}

How does SP evoke an inward current in those neostriatal neurons? As previous studies on other types of neurons have suggested, voltage-dependent $\mathrm{Ca}^{2+}$ channels, voltage-dependent $\mathrm{K}^{+}$ channels, $\mathrm{Cl}^{-}$channels, and nonselective cation channels are the potential candidates. There possibly is also involvement of hyperpolarization-activated cation channels and voltagedependent $\mathrm{Na}^{+}$channels. Modulation of these channels would induce an inward current. A role for TTX-sensitive voltagedependent $\mathrm{Na}^{+}$channels, however, can be ruled out first because the inward current was invariably observed in the presence of TTX by application of SP as shown in Figures 3-5. In addition, $\mathrm{Cl}^{-}$channels can be omitted from the list of the candidates, because of the closeness of the equilibrium potential (about -52 $\mathrm{mV}$ ) to the average resting membrane potential of the large aspiny neurons $(-60 \mathrm{mV})$. 


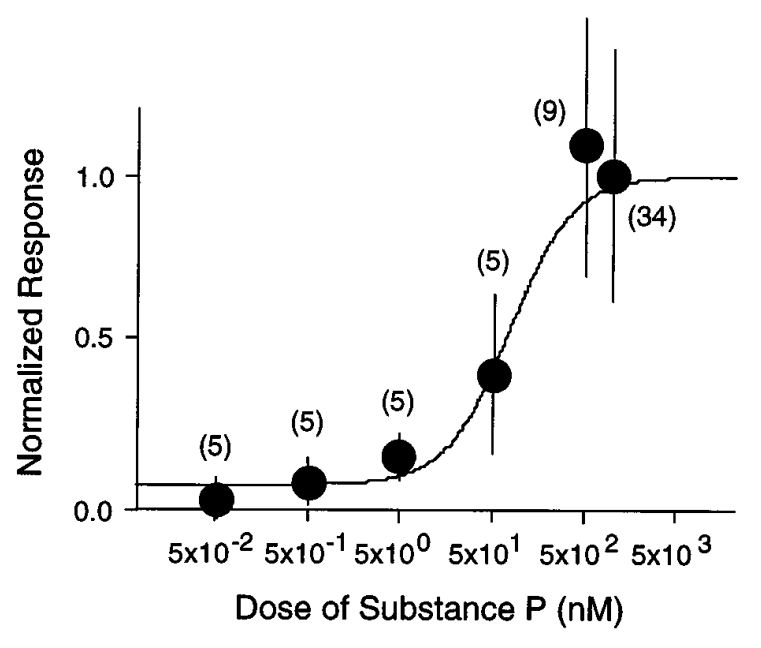

Figure 4. Dose-response curve for substance P-induced inward current evoked at a membrane potential of $-60 \mathrm{mV}$ in the large aspiny neurons of the neostriatum. Each point and vertical bar represents mean \pm SD. Numbers in parentheses refer to numbers of test cells.

The SP effect is unchanged in a solution containing blockers for $\mathrm{Ca}^{2+}$ channels

The contribution of calcium $\left(\mathrm{Ca}^{2+}\right)$ channel conductances was assessed first, therefore, by switching a control saline solution to a $\mathrm{Ca}^{2+}$-free/ $\mathrm{Co}^{2+}$-containing solution during recording. In some experiments, $5 \mu \mathrm{M}$ nifedipine was also added to the test solution to ensure suppression of the L-type $\mathrm{Ca}^{2+}$ channel currents. As shown in Figure $6 A$, the SP-evoked inward current did not change its amplitude significantly after addition of $\mathrm{Co}^{2+}$ to the external solution (see arrows). The average SP-evoked inward current in the presence of $\mathrm{Ca}^{2+}$ channel blockers was $-102 \pm 35.3 \mathrm{pA}(n=$ 12) and was not statistically different from the control solution value $(-81.2 \pm 36.7 \mathrm{pA}, n=40)$ (see also Fig. 9).

\section{The SP effect is unchanged in a solution containing blockers} for $\mathrm{I}_{h}$

We next studied the effect of blockade of the hyperpolarizationactivated cation current $\left(I_{\mathrm{h}}\right)$ on the SP-induced inward current by adding $2 \mathrm{mM} \mathrm{Cs}^{+}$to the external solution, because the $I_{\mathrm{h}}$ of the large aspiny neurons is so prominent that it is thought to contribute to their characteristic tonic firing properties, together with their prolonged afterhyperpolarization. This procedure also suppresses the inwardly rectifying potassium channel $\left(I_{\mathrm{Kir}}\right)$ if present in the large aspiny neurons. However, according to Jiang and North (1991), the $I_{\text {Kir }}$ is absent in the "secondary cells," considered to correspond to the large aspiny neurons in this study. The slow inward relaxation observed with step hyperpolarizations is considered to be attributable mainly to opening of the $I_{\mathrm{h}}$ channels, because of its slower time course and reduction of amplitude in low sodium external solution (data not shown). As illustrated in Figure $6 B$, addition of $\mathrm{Cs}^{+}$abolished slow inward relaxation rapidly and reversibly, but the current evoked by SP was little affected (see arrows). The peak current evoked by SP was $-81.2 \pm$ $36.7 \mathrm{pA}$ in control solution $(n=40)$, and $-82.1 \pm 32.9 \mathrm{pA}$ in $\mathrm{Cs}^{+}$-containing solution $(n=8$; see also Fig. 9). In fact, SP $(0.5-1.0 \mu \mathrm{M})$ reduced the amplitude of $I_{\mathrm{h}}$ by $15.9 \%(n=16)$ in the control solution. These results clearly indicate that $I_{\mathrm{h}}$ does not play a role in generation of the inward current by SP.

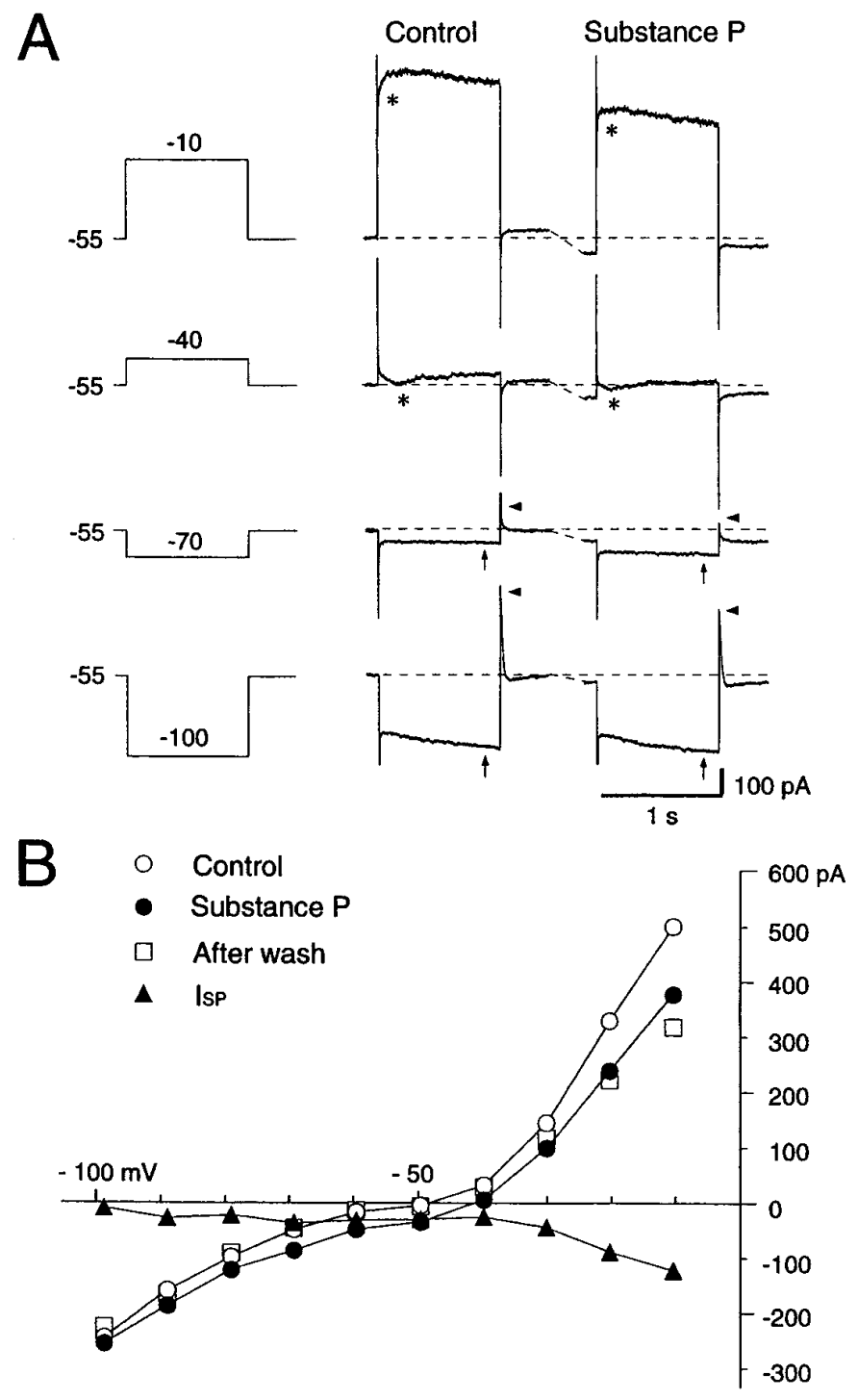

Figure 5. Effects of SP on a voltage-clamped large aspiny neuron bathed in normal saline containing TTX $(0.3 \mu \mathrm{M}) . A$, Current responses to step pulses $(-100,-70,-40$, and $-10 \mathrm{mV})$ before (Control) and during the SP application. A prominent sag (arrows) at the hyperpolarizing pulse of $-100 \mathrm{mV}$ and a fast outward transient (arrowheads) on cessation of hyperpolarization are present. Depolarizing step pulses more positive than $-40 \mathrm{mV}$ evoked an inward current (asterisks). SP evoked an inward shift of the holding current. $B$, Steady-state $I-V$ curves before $(\bigcirc)$, during exposure to (-), and after washout $(\square)$ of SP. The curves were constructed from the measurements of current level attained at the end of each $1 \mathrm{sec}$ hyperpolarizing or depolarizing voltage step before, during, and after SP application. The $I-V$ curve for $I_{\mathrm{SP}}$ was obtained by subtraction of the control from the SP values $(\boldsymbol{\Lambda})$. Slope conductance decreased in the suprathreshold region, increased at resting membrane potential levels, and decreased again at potentials more negative than $-70 \mathrm{mV}$ during SP application.

\section{Little contribution of $\mathrm{K}^{+}$channels to the SP-induced inward current}

The contribution of $\mathrm{K}^{+}$channels to the inward current was also assessed by comparing current amplitude in the control solution to that in an external solution, in which $\mathrm{K}^{+}$channels and other voltage-dependent channels were all blocked by addition of TEA (30 mM), 4-AP (5 mM), $\mathrm{Cs}^{+}(2 \mathrm{mM}), \mathrm{Mg}^{2+}(3.6 \mathrm{~mm})$, nominally free $\mathrm{Ca}^{2+}$, nifedipine $(5 \mu \mathrm{M})$, and TTX $(0.3 \mu \mathrm{M})$, and Cs- 

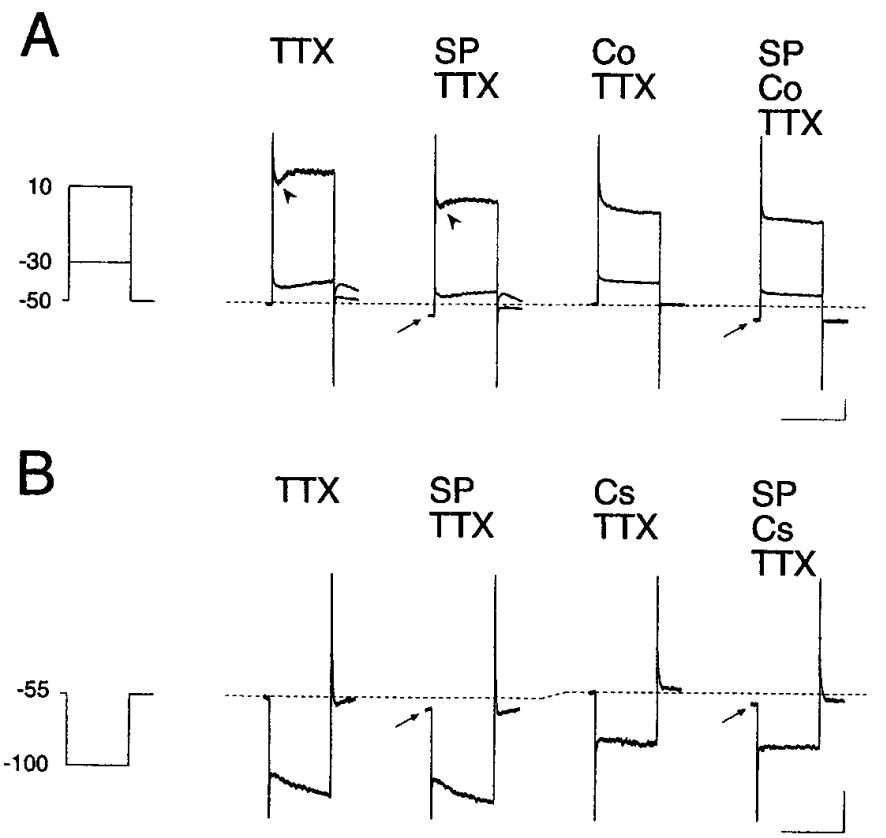

Figure 6. $\mathrm{Ca}^{2+}$ channels and hyperpolarization-activated cation channels $\left(I_{\mathrm{h}}\right)$ do not contribute to the SP-induced inward current. In $A, \mathrm{Ca}^{2+}$ was replaced by $\mathrm{Co}^{2+}(2.4 \mathrm{mM})$ in the external solution. The rapidly decaying current was suppressed by SP application (arrowheads). In $B, \mathrm{Cs}^{+}$(2 mM) was added to the test solution. TTX was contained in the external solution at $0.3 \mu \mathrm{M}$ in $A$ and $B$. The amplitude of the inward shift of the holding potential during SP application was unchanged either in $\mathrm{Co}^{2+}$-containing or in $\mathrm{Cs}^{+}$-containing solutions (arrows). Calibration in $A$ and $B: 1 \mathrm{sec}$ (horizontal), $100 \mathrm{pA}$ (vertical).

methanesulfonate was present in the recording pipette. In this experiment, the control and test solutions contained the same concentrations of $\mathrm{Na}^{+}(115 \mathrm{~mm})$ and $\mathrm{K}^{+}$ions $(3 \mathrm{~mm})$, and the cells were voltage-clamped around $-60 \mathrm{mV}$. As a result, we found that the current evoked in the control solution $(-64.0 \pm 9.4 \mathrm{pA}$, $n=7$ ) was not significantly different from that in the test solution $(-56.5 \pm 27.4 \mathrm{pA}, n=34$; Fig. 9). This suggests that modulation of $\mathrm{K}^{+}$channel conductances, even if it occurs, does not significantly contribute to the inward current at the resting membrane potential level.

We conclude from these results that voltage-dependent $\mathrm{Na}^{+}$, $\mathrm{Ca}^{2+}$, and $\mathrm{K}^{+}$channels and $I_{\mathrm{h}}$ channels do not contribute significantly to the SP-induced inward current and that there must be some other NK1-receptor-operated channel conductance in the large aspiny neurons that might account for the observed inward current. To test for the existence of a nonselective cation channel, we first undertook the series of experiments stated to examine whether the SP-operated channels let cations through nonselectively.

\section{The SP current is carried mainly by sodium ions in the large aspiny neurons}

First, we tested the role of $\mathrm{Na}^{+}$ions by substituting them with choline in the current in response to SP. As shown in Figure 7, the evoked inward currents by SP in a solution containing $151 \mathrm{~mm}$ $\mathrm{Na}^{+}$ions (Fig. 7Aa) showed a remarkable reduction when the solution was switched to a solution containing $27 \mathrm{mM} \mathrm{Na}^{+}$ions (Fig. 7Ab). Overall, average amplitude of the current evoked in saline containing $151 \mathrm{mM} \mathrm{Na}^{+}$ions was $-81.2 \pm 36.7 \mathrm{pA}(n=40)$, significantly lower than that in a low- $\mathrm{Na}^{+}(27 \mathrm{mM})$ solution $(-13.6 \pm 10.2 \mathrm{pA}, n=6, p<0.05)$. Although the lack of a space clamp might affect the apparent $I-V$ relationship, especially in the suprathreshold levels, the $I-V$ plots obtained by the ramp-pulse protocol showed: (1) a prominent outward rectification in the suprathreshold region and a small inward rectification in the subthreshold region; (2) that these rectifications were significantly suppressed during SP application, yielding more linear $I-V$ relationships; and (3) a significant reduction of the SP current in the subthreshold levels in a low- $\mathrm{Na}^{+}$solution (Fig. $7 B, I_{\mathrm{SP}}$ ). The large outward current seen in the suprathreshold levels might be attributable to opening of $\mathrm{K}^{+}$and $\mathrm{Ca}^{2+}$ channels, and the remarkable reduction of the outward current during SP application might suggest the SP-blocking action on either channel or both. However, at least at the physiological resting levels the contribution of blocking effects of either or both of the two kinds of channels would be negligible as described above.

We next tried to examine whether $\mathrm{K}^{+}$ions permeate this cation channel by raising extracellular $\mathrm{K}^{+}$concentrations. However, contrary to our expectation, we found that the current elicited in a high- $\mathrm{K}^{+}$solution $\left(\mathrm{K}^{+} 10 \mathrm{~mm}\right)$ showed only an insignificant slight reduction compared with that in a normal- $\mathrm{K}^{+}$solution, with respective values of $-40 \pm 28.5 \mathrm{pA}(n=19)$ and $-53.2 \pm 28.6 \mathrm{pA}$ $(n=37)$.

These observations strongly suggest that $\mathrm{Na}^{+}$ions are the major carrier of SP-evoked inward current. Because $\mathrm{Na}^{+}$channels are blocked by addition of TTX and a possible involvement of $I_{\mathrm{h}}$ channels has already been ruled out as described above, the results imply that the $\mathrm{Na}^{+}$ions carry the inward current through the TTX-insensitive nonselective cation channels opened by SP, as reported previously for the rat locus coeruleus and sensory neurons (Shen and North, 1992; Koyano et al., 1993; Inoue et al., 1995).

\section{TTX-insensitive cation channels}

We next isolated the TTX-insensitive cation channels and examined whether they pass $\mathrm{Na}^{+}$as well as $\mathrm{K}^{+}$ions by application of SP. The experimental procedures were similar for the study of $\mathrm{K}^{+}$-channel contribution to those described above, in which the bathing solution contained TEA (30 mM), 4-AP (5 mM), $\mathrm{Cs}^{+}(2$ $\mathrm{mM})$, high $\mathrm{Mg}^{2+}(3.6 \mathrm{mM})$, nifedipine $(5 \mu \mathrm{M})$, and TTX $(0.3 \mu \mathrm{M})$ with free $\mathrm{Ca}^{2+}$. Cs-methanesulfonate was also included in the patch pipette. The resulting $\mathrm{Na}^{+}$concentration was $115 \mathrm{~mm}$, and the $\mathrm{K}^{+}$concentration was $3 \mathrm{~mm}$ in the control solution. This configuration ruled out the possible involvement of voltagedependent $\mathrm{K}^{+}, \mathrm{Ca}^{2+}, \mathrm{Na}^{+}$, and $I_{\mathrm{h}}$ channels, and only the NK1receptor-operated cation channels remained intact. Figure $8 A$, which illustrates current traces obtained at $-100,-40,0$, and +10 $\mathrm{mV}$ step pulses before and during SP application, clearly indicates that SP elicited an inward shift of the holding current with an increase of membrane conductance. To test whether the SPinduced inward current through the TTX-insensitive cation channels depends on the external $\mathrm{Na}^{+}$concentration, we recorded the SP-induced currents at near-normal (115 mM) and low (26 mM) $\mathrm{Na}^{+}$concentrations. The $I-V$ plots, fairly linear compared with those taken in saline solution (see Figs. 5, 7), revealed that the reversal potential in the cell shown in Figure 8 was $\sim 26 \mathrm{mV}$, whereas bathing the cell in the low- $\mathrm{Na}^{+}$solution $\left(\mathrm{Na}^{+} 26 \mathrm{~mm}\right)$ reduced the amplitude of SP-evoked current and also the reversal potential to $13 \mathrm{mV}$. The amplitude of the current at low $\mathrm{Na}^{+}$ concentration was statistically lower than that at higher $\mathrm{Na}^{+}$ concentration $(p<0.01)$. On average, the amplitude of the current was $-53.2 \pm 28.6 \mathrm{pA}(n=37)$ at a $\mathrm{Na}^{+}$concentration of $115 \mathrm{~mm}$ in this configuration, and $-15.0 \pm 20.4 \mathrm{pA}(n=13)$ at 26 


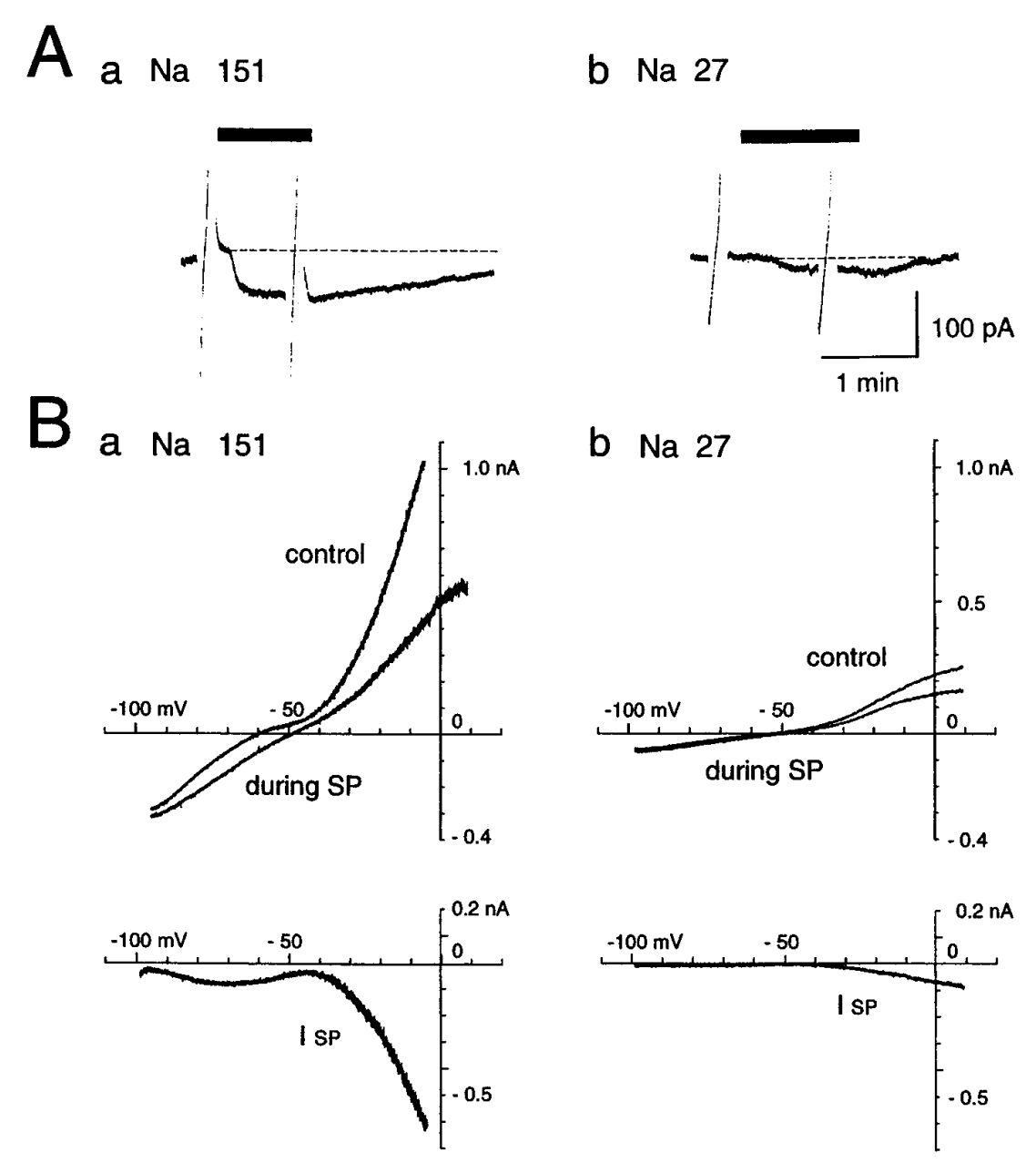

Figure 7. Effects of SP $(1 \mu \mathrm{M})$ in a low $(27 \mathrm{~mm})$ - or control $(151 \mathrm{~mm})-\mathrm{Na}^{+}$solution. $\mathrm{NaCl}$ was replaced by choline- $\mathrm{Cl}$ in the low- $\mathrm{Na}^{+}$solution. Ramp voltage pulses (from -100 to $10 \mathrm{mV}, 40 \mathrm{sec}$ ) were applied before and during the application of SP. TTX $(0.3 \mathrm{M})$ was applied throughout the experiment. $A$, The SP-induced current was substantially decreased in the low- $\mathrm{Na}^{+}$solution. $B$, $I-V$ curves before and during SP application obtained in the normal $(a)$ - and low $(b)$-Na solutions. The SPinduced current $\left(I_{\mathrm{SP}}\right)$ curve was constructed by subtracting the $I-V$ curve obtained before SP application from the curve obtained during the peptide application. Note the dramatic reduction of $I_{\mathrm{SP}}$ in a low- $\mathrm{Na}^{+}$solution.
mM. The significant negative shift of the reversal potential from $53.6 \mathrm{mV}(n=27)$ at the $\mathrm{Na}^{+}$concentration of $115 \mathrm{~mm}$ to $27.8 \mathrm{mV}$ $(n=27)$ at $26 \mathrm{~mm}$ also supported the view that the conductances remaining unblocked were of $\mathrm{Na}^{+}$-permeable cation channel type, although accurate quantitative measurement of the reversal potentials was impossible because of the space-clamp errors in the widespread dendritic and axonal fields of the large aspiny neurons.

We next tried to examine whether $\mathrm{K}^{+}$ions permeate this TTX-insensitive cation channel by raising extracellular $\mathrm{K}^{+}$concentrations. First, including Cs-methanesulfonate $(120 \mathrm{~mm})$ in the patch solutions, we compared the amplitude of the SP-induced current obtained in normal- $\mathrm{K}^{+}(3 \mathrm{~mm})$ and low- $\mathrm{Na}^{+}(26 \mathrm{~mm})$ extracellular solution with that in high- $\mathrm{K}^{+}(30 \mathrm{~mm})$ and low- $\mathrm{Na}^{+}$ (26 mM) solution. $\mathrm{Na}^{+}$concentration was lowered to maximize the effect of raising the $\mathrm{K}^{+}$concentration. The results were $-15.0 \pm 20.4 \mathrm{pA}(n=13)$ in normal- $\mathrm{K}^{+}(3 \mathrm{~mm}) / \mathrm{low}-\mathrm{Na}^{+}$and $-16.0 \pm 13.0 \mathrm{pA}$ in high- $\mathrm{K}^{+}(30 \mathrm{~mm}) / \mathrm{low}-\mathrm{Na}^{+}$solution without any significant difference. Considering the possibility that this lack of effect of raising the $\mathrm{K}$ concentration might be attributable to masking by high permeability of $\mathrm{Cs}^{+}$ions through the nonselective cation channels, in line with the report by Inoue et al. (1995) that $\mathrm{Cs}^{+}$ions pass through the channels in dissociated rat dorsal root ganglion neurons as easily as $\mathrm{Na}^{+}$ions (relative permeability $\left.P_{\mathrm{Cs}} / P_{\mathrm{Na}}=1.10\right)$, another experiment was conducted using TEA-Cl (120 mM) in place of Cs-methanesulfonate because it was reported to be less permeable (relative permeability $P_{\mathrm{TEA}} / P_{\mathrm{Na}}=$
0.28). However, the results were again disappointing and statistically nonsignificant: $-4.7 \pm 44.9 \mathrm{pA}(n=19)$ in normal- $\mathrm{K}^{+}(3$ $\mathrm{mm}) / \mathrm{low}-\mathrm{Na}^{+}$and $-13.8 \pm 12.5 \mathrm{pA}(n=17)$ in high-K ${ }^{+}(30$ $\mathrm{mm}) /$ low- $\mathrm{Na}^{+}$solution.

These results can be interpreted again as a result of an insufficient space clamp because, if the neurons were completely voltage-clamped at the resting voltage levels throughout, from the somata to the dendrites, bathing the neurons in a high- $\mathrm{K}^{+}$solution would reduce the outflow of $\mathrm{K}^{+}$ions and thereby increase the SP-evoked inward current. This discrepancy clearly points to the neurons not being isopotential. If the voltage clamp were incomplete because of the space-clamp limitation, the dendritic region would become depolarized. This depolarization would reduce the driving force of the inward $\mathrm{Na}^{+}$flux and reduce the inflow of $\mathrm{Na}^{+}$ ions into the dendrites, thereby masking the increase of the inward current caused by the reduction of $\mathrm{K}^{+}$ion outflow, as observed in these experiments. This interpretation is supported by the previous immunohistochemical findings that the plasma membrane of neuronal cell bodies and dendrites (even thin dendrites) of the striatal large aspiny neurons and neurons of other brain areas demonstrates intense SP-receptor immunoreactivity, whereas no profiles of axon terminals are immunoreactive (Kaneko et al., 1993; Shigemoto et al., 1993; Liu et al., 1994; Mantyh et al., 1995; Parent et al., 1995). Furthermore, electron microscopic studies revealed that reaction products frequently are (Shigemoto et al., 1993; Liu et al., 1994), suggesting that SP found at the postsynaptic specializations and extrasynaptic sites 
A

$\mathrm{Na} 115$

with blockers for $\mathrm{Na}, \mathrm{K}$, $\mathrm{Ca}$ and Ih channels

$-55$

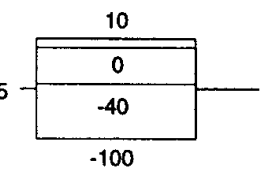

B a Na 26

with blockers for $\mathrm{Na}, \mathrm{K}$, $\mathrm{Ca}$ and Ih channels
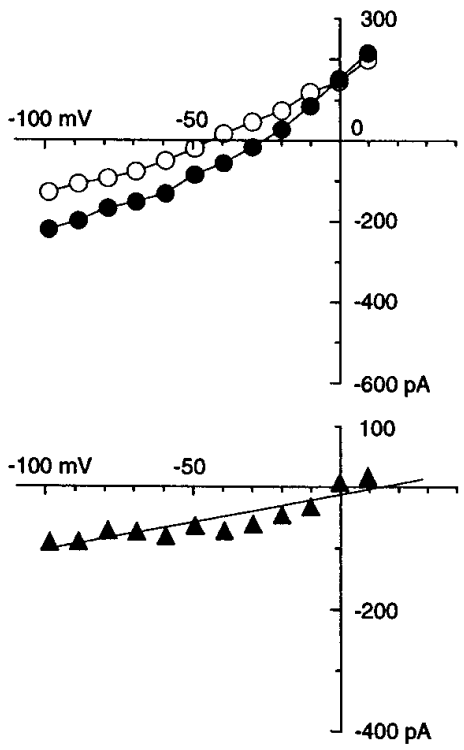

Control

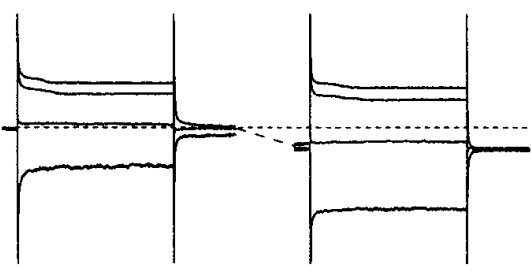

with blockers for $\mathrm{Na}, \mathrm{K}$, $\mathrm{Ca}$ and $\mathrm{lh}$ channels
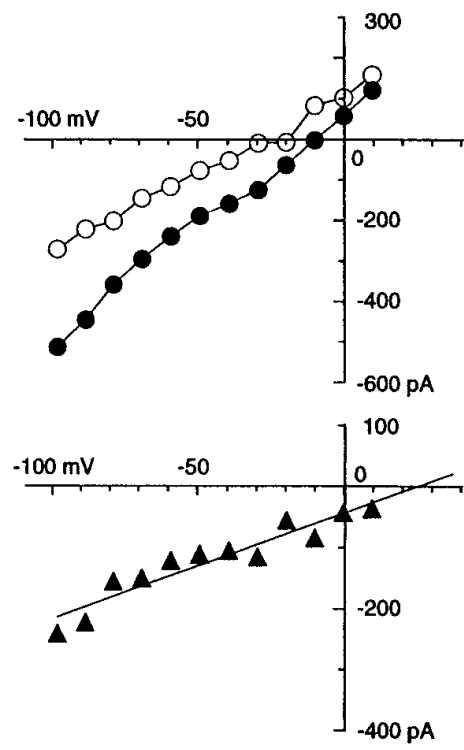

Figure 8. Effects of SP $(1 \mu \mathrm{M})$ on nonselective cation channels in a low (26 mM)- or normal (115 mM)-Na solution. $\mathrm{NaCl}$ was replaced by choline-Cl. In this experiment, $\mathrm{K}^{+}, I_{\mathrm{h}}, \mathrm{Na}^{+}$, and $\mathrm{Ca}^{2+}$ channel conductances were all suppressed by the addition of TEA (30 mM), 4-AP (5 $\mathrm{mM}), \mathrm{Cs}^{+}(2 \mathrm{mM}), \mathrm{Mg}^{2+}(3.6 \mathrm{mM})$, or TTX $(0.3 \mathrm{M})$ to the external solution, and Cs-methanesulfonate $(120 \mathrm{~mm})$ to the internal solution. $\mathrm{CaCl}_{2}$ was omitted from the external solution. Note the substantially smaller SP-induced current in the low- $\mathrm{Na}^{+}$solution than in the normal- $\mathrm{Na}^{+}$ solution. $\bigcirc$, Control; $\bullet$, substance $\mathrm{P}$ responses; $\boldsymbol{\Delta}, I_{\mathrm{SP}}$. evokes the inward current from the somata to widespread thin dendrites of the cells.

We conclude from these results that under physiological conditions the $\mathrm{Na}^{+}$inflow attributable to opening of TTX-insensitive cation channels would account for almost all of the inward current observed during SP application in the case of striatal cholinergic neurons, but we could not provide evidence in our experimental configuration that the cation channels are nonselective.

\section{SP effects on other types of neostriatal neurons}

Of the 7 neurons identified as LTS cells, 6 were tested for SP actions. Among them, 4 responded and 2 showed no response to bath-applied SP. On the other hand, none of the cells identified as FS cells ( $3 / 3$ cells) or as medium spiny neurons ( $6 / 6$ cells) showed response to the bath-applied SP. Figure 10 illustrates examples for LTS cells that responded to a bath-applied SP of $1 \mu \mathrm{M}$. The cells had widespread aspiny dendrites and extended axons. The current injection evoked characteristic bursts on positive current commands at the beginning of current-clamp recording with $\mathrm{Cs}^{+}$-filled pipettes (Fig. 10Ac). As shown previously for the large aspiny neurons, SP evoked an inward current in the LTS cells even after blockade of $\mathrm{K}^{+}, \mathrm{Na}^{+}, \mathrm{Ca}^{2+}$, and $I_{\mathrm{h}}$ channels (Fig. 10B). Lowering the $\mathrm{Na}^{+}$concentration also caused a small decrease in the current with a negative shift of the reversal potential $(n=2$; data not shown). These results strongly suggest that these neurons might share a common mechanism with the large aspiny neurons in terms of the SP action.

\section{DISCUSSION}

The aims of this study were to determine the types of neurons in the striatum that respond to SP and to elucidate the key mechanisms responsible for its actions. The results reported here indicate that: (1) only the large aspiny cholinergic interneurons (LA cells) and LTS cells (somatostatin/NOS-containing medium-sized aspiny interneurons) depolarize membrane potentials in response to SP, whereas no responses are evoked in the FS cells (parvalbumin-positive interneurons) and medium spiny projection neurons; (2) SP depolarizes the large aspiny neurons mainly by opening the TTX-insensitive cation channels rather than decreasing the $\mathrm{K}^{+}$-channel conductance at resting levels; (3) the LTS cells appear, at least in part, to share this common ionic mechanism with the large aspiny neurons in terms of the actions of SP; and (4) the SP released from intrastriatal fiber terminals might evoke slow EPSPs lasting for $\sim 1 \mathrm{~min}$ in the large aspiny neurons.

In situ hybridization histochemistry has revealed that SPreceptor mRNA is selectively localized in the cholinergic neurons in the rat striatum, as well as in the medial septum and basal forebrain cell groups, and that there are also SP-receptorcontaining neurons that are not cholinergic in the striatum (Gerfen, 1991; Aubry et al., 1993). Immunohistochemical findings later demonstrated the latter to be medium-sized aspiny somatostatinergic interneurons (Shigemoto et al., 1993; Kaneko et al., 1993). None of the studies reported the presence of SP receptors in the medium-sized spiny projection neurons 


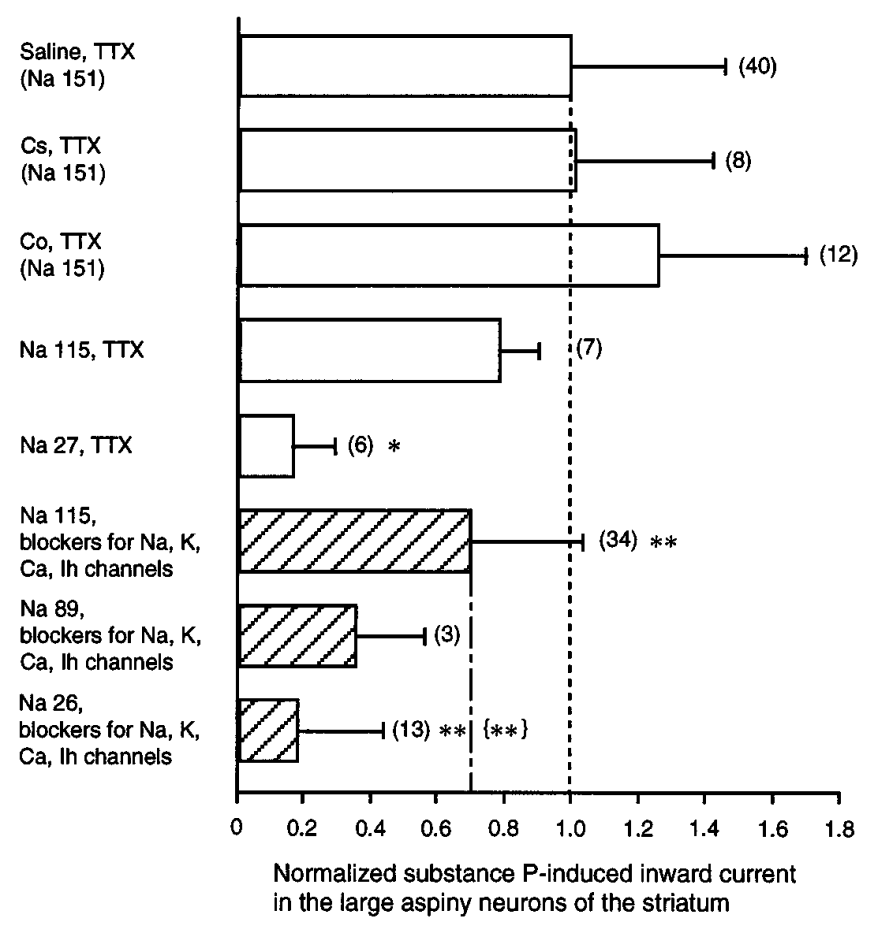

Figure 9. SP-induced inward shift of the holding current at the resting potential in solutions of differing ionic composition. The inward shift is illustrated as the ratio to the shift recorded in the control saline solution containing TTX $(0.3 \mu \mathrm{M})($ mean $\pm \mathrm{SD}=-81.2 \pm 36.7 \mathrm{pA})$. SDs are shown with bars. Numbers in parentheses refer to numbers of test cells. The external solutions tested were: saline $\left(\mathrm{Na}^{+} 151 \mathrm{~mm}\right)$ with TTX, saline with $\mathrm{Cs}^{+}(2 \mathrm{mM})$ and TTX, saline with $\mathrm{Co}^{2+}(2 \mathrm{~mm})$ and TTX, low-Na ${ }^{+}(115$ mM) solution with TTX, low- $\mathrm{Na}^{+}(27 \mathrm{~mm})$ solution with TTX, and solutions for study of the nonselective cation channel (hatched bars), which included TEA (30 mM), 4-AP (10 mM), $\mathrm{Mg}^{2+}$ (3.6 mM), no $\mathrm{Ca}^{2+}, \mathrm{Cs}^{+}(2$ $\mathrm{mM})$, and TTX. Occasionally, nifedipine $(5 \mu \mathrm{M})$ was added. The internal solution contained Cs-methanesulfonate in the study of the nonselective cation channel. Comparisons were made with the Student's $t$ test against the same group of neurons tested in the control saline solution $\left(^{*} p<0.05\right.$, significant; $* * p<0.01$, very significant) or in the solutions containing blockers for $\mathrm{Na}^{+}, \mathrm{K}^{+}, \mathrm{Ca}^{2+}$, and $I_{\mathrm{h}}$ channels ${ }^{{ }^{\{* *} p} p<0.01$, very significant).

of the striatum or in neurons of the substantia nigra pars reticulata. Our findings are in agreement with these previous histochemical studies in that all of the large aspiny neurons and some of the LTS cells (presumably somatostatinergic), but none of the medium spiny neurons or FS cells (parvalbumin cells), responded to the bath-applied SP. Our data also suggest that SP probably acts directly on these neurons, and not through activation of a distinct cell population, because its action was observed in TTX-containing $\mathrm{Ca}^{2+}$-free solutions.

SP excites the large aspiny neurons by depolarization, caused primarily by an increase in cation conductance, rather than a decrease in the $\mathrm{K}^{+}$conductance at the resting membrane potential levels. The main evidence for the cation conductance increase is as follows. First, although estimation of the reversal potential is hampered by space-clamp errors, the current was found to reverse around $>20 \mathrm{mV}$. Second, it was reduced in low- $\mathrm{Na}^{+}$concentrations. Third, it was not significantly different from that measured when voltage-dependent $\mathrm{K}^{+}$, as well as $I_{\mathrm{h}}$, $\mathrm{Na}^{+}$and $\mathrm{Ca}^{2+}$ channels were all blocked. The ionic mechanisms of SP actions seem to vary considerably among cell types.
Murase et al. (1989) reported that the increment in $\mathrm{Ca}^{2+}$ current attributable to SP, together with an increase in nonspecific cationic permeability, contributes to the inward current in the spinal dorsal horn neurons, but other studies of sympathetic neurons (Bley and Tsien, 1990) showed an inhibition of $\mathrm{N}$-type $\mathrm{Ca}^{2+}$ and M-currents, as well as an induction of leak current. In the striatal large aspiny neurons, suppression of $\mathrm{Ca}^{2+}$ currents by switching to $\mathrm{Ca}^{2+}$-free and $\mathrm{Co}^{2+}$ - and nifedipine-containing solution did not significantly change the amplitude of SP-induced current. Suppression of an inward rectifier by SP has been demonstrated to excite the cholinergic neurons in the basal forebrain (Stanfield et al., 1985; Yamaguchi et al., 1990) or other types of neurons (Koyano et al., 1993), but the same cholinergic neurons in the neostriatum have little or no inward rectifier (Jiang and North, 1991) and, therefore, it could not be involved in the present case. Modulation of the M-current by SP is also known in some neurons (Hosli et al., 1981; Nowak and MacDonald, 1982; Adams et al., 1983; Vanner et al., 1993) but, again, it was not detected in our study. Although the $I_{\mathrm{h}}$ current was prominent in our large aspiny cells, together with their prolonged afterhyperpolarization, being considered responsible for maintaining the resting membrane potential at about $-60 \mathrm{mV}$ and endowing them with tonic firing properties, it did not appear to contribute to the SP current because no change in amplitude was noted after suppression of $I_{\mathrm{h}}$ with $\mathrm{Cs}^{+}$. An involvement of $\mathrm{Cl}^{-}$conductance is also unlikely (Bertrand and Galligan, 1994), because the equilibrium potential for the $\mathrm{Cl}^{-}$ions would be less than $-52 \mathrm{mV}$, which is close to the resting membrane potential of the neurons, assuming that the ion concentrations of the cells become almost equal to that of the patch-pipette solution. Although our experiments by no means excluded the possible blocking actions of SP on channels such as $\mathrm{K}^{+}$and $\mathrm{Ca}^{2+}$ at the suprathreshold levels, our findings strongly imply that the SP-induced TTXinsensitive cation current accounts for virtually all of the inward current at rest in the large aspiny interneurons. However, because of the space-clamp errors in our experimental configuration in which the dendrites and axons of the neurons were well preserved, the question of whether the cation channels are nonselective, as described in other studies, still remains to be elucidated. Using dissociated or cultured neurons instead of slice preparations should allow resolution of this point.

There have been at least three possible sources of SP-positive terminals reported, the center median-parafascicular complex (cm-pf) of the thalamus, and the two types of medium-sized striatal neuron: the medium-sized interneurons with indented nucleus and the medium-sized spiny projection neurons. However, among these three, the major source of SP terminals is probably the striatonigral medium spiny neurons (Bolam et al., 1986). Although the striatal cholinergic neurons receive massive synaptic inputs from the thalamus (Lapper and Bolam, 1992), the SP-containing thalamostriatal projections may be very weak because it has been reported that all SP-immunoreactive axonal boutons form symmetrical synaptic specializations, whereas the striatal afferents from the $\mathrm{cm}$-pf form synaptic contacts with asymmetrical membrane specializations (Bolam et al., 1983; Bolam and Izzo, 1988).

The large aspiny interneurons of the neostriatum have large somata and a widespread dendritic field (up to $1 \mathrm{~mm}$ from the soma) that extends into both patch and matrix compartments (Penny et al., 1988; Kawaguchi, 1992). The axons are even more extended and preferentially innervate the matrix compartment. 


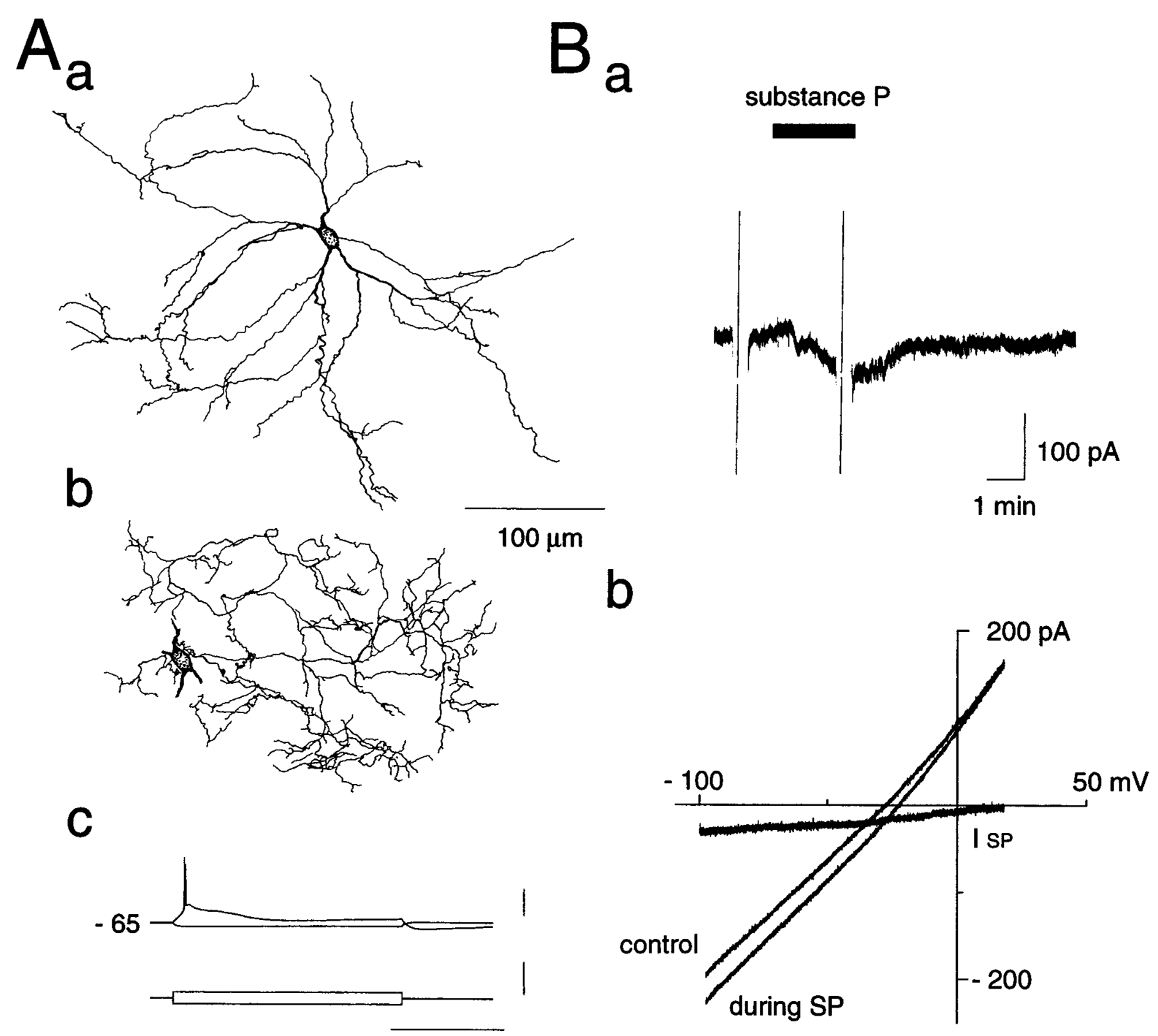

Figure 10. Actions of SP on identified LTS cells in the neostriatum. $A$, Morphology of an LTS cell. Dendrites $(a)$ and an axon $(b)$ are reconstructed. $c$, A burst of action potentials, a characteristic of the LTS cells, seen immediately after breaking a patch membrane in the normal saline solution. Calibration bars: $40 \mathrm{mV}, 400 \mathrm{pA}, 500 \mathrm{msec}$ (from top to bottom). B, Responses to SP in an identified LTS cell in an external solution containing TEA, 4-AP, Mg ${ }^{2+}$, no $\mathrm{Ca}^{2+}, \mathrm{Cs}^{+}$, and TTX with Cs-methanesulfonate in the pipette. Holding potential, $-55 \mathrm{mV} . a$, SP at $1 \mu \mathrm{M}$ evoked an inward current in the LTS cell. $b, I-V$ curve before and during SP application. The same cell as in $a$.

Their perikarya are more frequently found in the boundaries between the two compartments in rats and primates (Kubota and Kawaguchi, 1993; Aosaki et al., 1995), placing the cells in a suitable position for intercompartmental association. By contrast, although GABAergic synapses among the medium spiny neurons have been well documented, Jaeger et al. (1995) found no physiological evidence for inhibition between them and suggested the necessity for a remodeling of the common view that mutual inhibition among spiny projection neurons is a key principle for integration of the striatal function. In this regard, it is important to explore the functional roles of each type of striatal interneuron.

The results of the present and previous studies raise some interesting questions concerning the way in which information is handled in the striatum. The medium spiny neurons are usually very silent, being intermittently phasically activated when they fire several action potentials (Wilson, 1993). It is reasonable to speculate that this episodic firing of the SP-containing medium spiny neurons would evoke a long-lasting EPSP in the large aspiny neurons by releasing SP, as suggested in our study. This evoked EPSP would easily raise the firing probability of the neurons because their membranes are restricted to such a narrow range of subthreshold potentials that a couple of excitatory synaptic inputs are sufficient for generation of action potentials in the cells (Wilson et al., 1990). As microdialysis studies have suggested, the released SP would increase acetylcholine release (Arenas et al., 1991; Anderson et al., 1993; Guevara Guzman et al., 1993) which, in turn, would stabilize the spiny projection neurons in either the enabled or the disabled state, depending on the status of cortical or thalamic input, by modulation of the A-current (Akins et al., 1990). Conversely, manipulation by reducing the firing probability of the large aspiny neurons would reduce its release, thereby attenuating the stability of the medium spiny neurons. This possibility is supported by a previous study by Jiang and North (1992) and by our study (Aosaki and Kawaguchi, 1995) in which the large aspiny neurons were inhibited by enkephalin through activation of the $\delta$-selective opioid receptor, which is coreleased with GABA 
from the terminals of striatopallidal medium spiny neurons. Thus, the activity of the large aspiny neurons of the striatum might be reciprocally regulated by striatonigral and striatopallidal medium spiny neurons. The striatal cholinergic neurons receive a major input from the parafascicular nucleus of the thalamus but very little from the cortex (Lapper and Bolam, 1992). The large aspiny neurons, therefore, would be expected to fire in a more exact temporal relationship to the pattern of firing of individual afferent fibers of the thalamostriatal (or corticostriatal) neurons, when they are activated by the released SP from the striatonigral neurons.

\section{REFERENCES}

Adams PR, Brown DA, Jones SW (1983) Substance P inhibits the M-current in bullfrog sympathetic neurones. Eur J Pharmacol 79:330-333. Akins PT, Surmeier DJ, Kitai ST (1990) Muscarinic modulation of a transient $\mathrm{K}^{+}$conductance in rat neostriatal neurons. Nature 344:240-242.

Anderson JJ, Chase TN, Engber TM (1993) Substance P increases release of acetylcholine in the dorsal striatum of freely moving rats. Brain Res 623:189-194.

Aosaki T, Kawaguchi Y (1995) Actions of neuropeptides on large aspiny neurons of rat neostriatum in vitro. Soc Neurosci Abstr 21:913.

Aosaki T, Graybiel AM, Kimura M (1994a) Effects of the nigrostriatal dopamine system on acquired neural responses in the striatum of behaving monkeys. Science 265:412-415.

Aosaki T, Tsubokawa H, Ishida A, Watanabe K, Graybiel AM, Kimura M (1994b) Responses of tonically active neurons in the primate's striatum undergo systematic changes during behavioral sensory-motor conditioning. J Neurosci 14:3969-3984.

Aosaki T, Kimura M, Graybiel AM (1995) Temporal and spatial characteristics of the tonically active neurons of the primate's striatum. J Neurophysiol 73:1234-1252.

Arenas E, Alberch I, Perz-Navarro E, Solsona C, Marsal J (1991) Neurokinin receptors differentially mediate endogenous acetylcholine release evoked by tachykinin in the neostriatum. J Neurosci 11:2332-2338.

Aubry JM, Lundstroem K, Kawashima E, Ayala G, Schulz P, Bartaunusz V, Kiss JZ (1994) NK1 receptor expression by cholinergic interneurons in human striatum. NeuroReport 5:1597-1600.

Bertrand PP, Galligan JJ (1994) Contribution of chloride conductance increase of slow EPSC and tachykinin current in guinea-pig myenteric neurones. J Physiol (Lond) 481:47-60.

Bley KR, Tsien RW (1990) Inhibition of $\mathrm{Ca}^{2+}$ and $\mathrm{K}^{+}$channels in sympathetic neurons by neuropeptides and other ganglionic transmitters. Neuron 2:379-391.

Bolam JP, Izzo PN (1988) The postsynaptic targets of substance $\mathrm{P}$-immunoreactive terminals in the rat neostriatum with particular reference to identified spiny striatonigral neurons. Exp Brain Res 70:361-377.

Bolam JP, Somogyi P, Takagi H, Fodor I, Smith AD (1983) Localization of substance P-like immunoreactivity in neurons and nerve terminals in the neostriatum of the rat: a correlated light and electron microscopic study. J Neurocytol 12:325-344.

Bolam JP, Ingham CA, Izzo PN, Levey AI, Rye DB, Smith AD, Wainer BH (1986) Substance P-containing terminals in synaptic contact with cholinergic neurons in the neostriatum and basal forebrain: a double immunocytochemical study in the rat. Brain Res 397:279-289.

Brownstein MJ, Mroz EA, Tappaz ML, Leeman SE (1977) On the origin of substance $P$ and glutamic acid decarboxylase (GAD) in the substantia nigra. Brain Res 135:315-323.

Edwards FA, Konnerth A, Sakmann B Takahashi T (1989) A thin slice preparation for patch clamp recordings from neurones of the mammalian central nervous system. Pflügers Arch 414:600-612.

Gerfen CR (1991) Substance P (neurokinin-1) receptor mRNA is selectively expressed in cholinergic neurons in the striatum and basal forebrain. Brain Res 556:165-170.

Gerfen CJ, Young WS (1988) Distribution of striatonigral and striatopallidal peptidergic neurons in both patch and matrix compartments: an in situ hybridization histochemistry and fluorescent retrograde tracing study. Brain Res 460:161-167.
Graybiel AM, Aosaki T, Flaherty AW, Kimura M (1994) The basal ganglia and adaptive motor control. Science 265:1826-1831.

Guevara Guzman R, Kendrick KM, Emson PC (1993) Effect of substance $\mathrm{P}$ on acetylcholine and dopamine release in the rat striatum: a microdialysis study. Brain Res 622:147-154.

Hong JS, Yang HYT, Costa E (1977) Projections of substance P containing neurons from neostriatum to substantia nigra. Brain Res 121:541-544.

Horikawa H, Armstrong WE (1988) A versatile means of intracellular labeling: injection of biocytin and its detection with avidin conjugates. J Neurosci Methods 25:1-11.

Hosli L, Hosli E, Zehntner C, Landolt H (1981) Effects of substance P on neurones and glial cells in cultured rat spinal cord. Neurosci Lett 24:165-168.

Inoue K, Nakazawa K, Inoue K, Fujimori K (1995) Nonselective cation channels coupled with tachykinin receptors in rat sensory neurons. J Neurophysiol 73:736-742.

Jaeger D, Kita H, Wilson CJ (1995) Surround inhibition among projection neurons is weak or nonexistent in the rat neostriatum. $\mathbf{J}$ Neurophysiol 72:2555-2558.

Jiang ZG, North RA (1991) Membrane properties and synaptic responses of rat striatal neurons in vitro. J Physiol (Lond) 443:533-553.

Jiang ZG, North RA (1992) Pre- and postsynaptic inhibition by opioids in rat striatum. $\mathrm{J}$ Neurosci 12:356-361.

Kaneko T, Shigemoto R, Nakanishi S, Mizuno N (1993) Substance P receptor-immunoreactive neurons in the rat neostriatum are segregated into somatostatinergic and cholinergic aspiny neurons. Brain Res 631:297-303.

Kawaguchi Y (1992) Large aspiny cells in the matrix of the rat neostriatum in vitro: physiological identification, relation to the compartments and excitatory postsynaptic currents. J Neurophysiol 67:1669-1682.

Kawaguchi Y (1993) Physiological, morphological, and histochemical characterization of three classes of interneurons in rat neostriatum. J Neurosci 13:4908-4923.

Kemp JM, Powell TPS (1971) The structure of the caudate nucleus of the cat: light and electron microscopy. Phil Trans $\mathrm{R}$ Soc Lond Biol 262:383-401.

Koyano K, Velimirovic BM, Grigg JJ, Nakajima S, Nakajima Y (1993) Two signal transduction mechanisms of substance P-induced depolarization in locus coeruleus neurons. Eur J Neurosci 5:1189-1197.

Kubota Y, Kawaguchi Y (1993) Spatial distributions of chemically identified intrinsic neurons in relation to patch and matrix compartments of rat neostriatum. J Comp Neurol 332:499-513.

Lapper SR, Bolam JP (1992) Input from prefrontal cortex and the parafascicular nucleus to cholinergic interneurons in the dorsal striatum of the rat. Neuroscience 51:533-545.

Le Gal La Salle G, Ben-Ari Y (1977) Microiontophoretic effects of substance $\mathrm{P}$ on neurons of the medial amygdala and putamen of the rat. Brain Res 135:174-179.

Liu H, Brown JL, Jasmin L, Maggio JE, Vigna SR, Mantyh PW, Basbaum AI (1994) Synaptic relationship between substance $P$ and the substance $P$ receptor: light and electron microscopic characterization of the mismatch between neuropeptides and their receptors. Proc Natl Acad Sci USA 91:1009-1013.

Mantyh PW, DeMaster E, Malhotra A, Ghilardi JR, Rogers SD, Mantyh CR, Liu H, Basbaum AI, Vigna SR, Maggio JE, Simone DA (1995) Receptor endocytosis and dendrite reshaping in spinal neurons after somatosensory stimulation. Science 268:1629-1632.

Murase K, Ryu PD, Randic M (1989) Tachykinins modulate multiple ionic conductances in voltage-clamped rat spinal dorsal horn neurons. J Neurophysiol 61:854-865.

Nowak LM, MacDonald RL (1982) Substance P ionic basis for depolarizing responses of mouse spinal cord neurons in cell culture. J Neurosci 2:1119-1128.

Otsuka M, Yoshioka K (1993) Neurotransmitter functions of mammalian tachykinins. Physiol Rev 73:229-308.

Parent A, Cicchetti F, Beach TG (1995) Striatal neurones displaying substance $\mathrm{P}$ (NK1) receptor immunoreactivity in human and nonhuman primates. NeuroReport 6:721-724.

Penny GR, Wilson CJ, Kitai ST (1988) Relationship of the axonal and dendritic geometry of spiny projection neurons to the compartmental organization of the neostriatum. J Comp Neurol 269:275-289.

Phelps PE, Houser CR, Vaughn JE (1985) Immunocytochemical localization of choline acetyltransferase within the rat neostriatum: a corre- 
lated light and electron microscopic study of cholinergic neurons and synapses. J Comp Neurol 238:286-307.

Shen KZ, North RA (1992) Substance P opens cation channels and closes potassium channels in rat locus coeruleus neurons. Neuroscience 50:345-353.

Shigemoto R, Nakaya Y, Nomura S, Ogawa-Meguro R, Ohishi H, Kaneko T, Nakanishi S, Mizuno N (1993) Immunocytochemical localization of rat substance $\mathrm{P}$ receptor in the striatum. Neurosci Lett 153:157-160.

Stanfield PR, Nakajima Y, Yamaguchi K (1985) Substance P raises neuronal membrane excitability by reducing inward rectification. Nature 315:498-501.

Sugimoto T, Takada M, Kaneko T, Mizuno N (1984) Substance $\mathrm{P}$-positive thalamocaudate neurons in the center median-parafascicular complex in the cat. Brain Res 323:181-184.
Vanner S, Evans RJ, Matsumoto SG, Surprenant A (1993) Potassium currents and their modulation by muscarine and substance $\mathrm{P}$ in neuronal cultures from adult guinea pig celiac ganglia. J Neurophysiol 69:1632-1644.

Wilson CJ (1993) The generation of natural firing patterns in neostriatal neurons. In: Progress in brain research. Chemical signalling in the basal ganglia (Arbuthnott GW, Emson PC, eds), pp 277-297. Amsterdam: Elsevier.

Wilson CJ, Chang HT, Kitai ST (1990) Firing patterns and synaptic potentials of identified giant aspiny interneurons in the rat neostriatum. J Neurosci 10:508-519.

Yamaguchi K, Nakajima Y, Nakajima S, Stanfield PR (1990) Modulation of inwardly rectifying channels by substance $\mathrm{P}$ in cholinergic neurones from rat brain in culture. J Physiol (Lond) 426:499-520. 